\title{
Comparative Study of Polypropylene and Aponeurotic Slings in the Treatment of Female Urinary Incontinence
}

\author{
Jorge A. Winckler, Jose G. L. Ramos, Bernadete M. Dalmolin, Diego C. Winckler, Marlene \\ Doring
}

University of Passo Fundo, Rio Grande do Sul, and Federal University of Rio Grande do Sul, Rio Grande do Sul, Brazil

\begin{abstract}
Purpose: Female stress urinary incontinence (SUI), the involuntary leakage of urine, is a highly prevalent social and hygiene problem, and various surgical techniques have been developed to correct it. This study used the technique of an aponeurosis sling made from the rectus abdominis muscle as a standard and compared the technique to a sling made with a polypropylene mesh, (Marlex $\left.{ }^{\circledR}\right)$.

Materials and Methods: From 2000 to 2007, 158 women who underwent surgery for SUI with an aponeurosis sling, (average age 55 years), were used as a standard for comparison with 316 women who underwent surgery with a polypropylene sling (average age 55 years).

Results: The mean follow-up period was 3.65 and 3.56 years for the respective groups. The aponeurosis group showed a cure of SUI in $128(81.0 \%)$, improvement in $23(14.6 \%)$, and failure in $7(4.4 \%)$. The polypropylene group showed a cure in $281(88.9 \%)$, improvement in $23(7.3 \%)$, and failure in $10(3.2 \%)(\mathrm{p}=0.083)$. Urgency was observed in $19(12 \%)$ of the aponeurosis group, and $28(8.9 \%)$ in the polypropylene group $(\mathrm{p}=0.320)$.

Conclusions: This study showed that the polypropylene mesh is an effective alternative to construct a sling for SUI in women. The results and rates of complication were comparable to the fascial sling from the rectus abdominis muscle aponeurosis.
\end{abstract}

Key words: urinary incontinence; stress; suburethral slings; polypropylenes

Int Braz J Urol. 2010; 36: 339-47

\section{INTRODUCTION}

Female stress urinary incontinence, classified as stress urinary incontinence (SUI) types I, II and III (1), is the objectively demonstrated involuntary leakage of urine. It is a social and hygiene problem, and results in high morbidity, social and sexual isolation, low self-esteem, and psychological trauma. It affects both job performance and home life (2) and is highly prevalent (3).

Historically, several surgical procedures have been developed for the treatment of female urinary incontinence: periurethral injection, transvaginal suspension, retropubic urethropexia, Burch's colposuspension, autologous fascial slings, laparoscopic colposuspension, AMS-800 artificial sphincter and procedures using pubovaginal belts and slings (410).

The objective of this study was to evaluate the use of a polypropylene mesh, (Marlex $\left.{ }^{\circledR}\right)$, to construct a pubovaginal sling for use in surgery to correct SUI in women, assessing the results, rate of extrusion/infection of the mesh, compared with a fascial sling made from the rectus abdominis aponeurosis. 


\section{MATERIALS AND METHODS}

In this surgical study for stress incontinence in women, we used the traditional technique of standard pubovaginal fascial sling and compared it with a sling that was made during the operation in which we use a segment of polypropylene mesh. The sling technique that was chosen for comparison in the study, always used a segment of polypropylene mesh (Marlex $\left.{ }^{\circledR}\right) 10$ x $1 \mathrm{~cm}$ with a pore size of $0.8 \mathrm{~mm}$, which is placed in the middle urethra dissected previously with 2 polyglactin sutures 2-0 on each side of the screen, and passed along the endopelvic fascia on both sides of the urethra through the retropubic space close to the pubis, leaving a mini skin incision above the pubic region then tied one side to the other without tension (Figure-1).

To make the sling fascial sheath of the rectus abdominis muscle, we made a transverse incision above the pubic area $10 \mathrm{~cm}$ long to remove a fragment of the aponeurosis of the rectus sheath $10 \mathrm{~cm}$ long and one inch wide. The region above the symphysis was conventionally reconstituted. We used a 2-0 polygla-

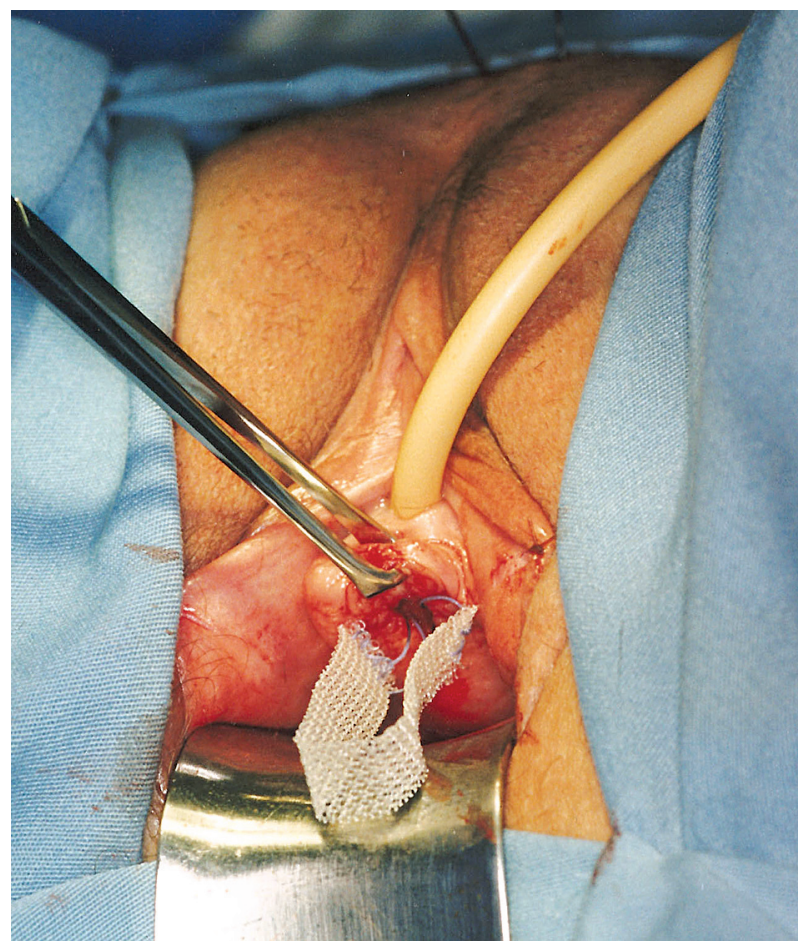

Figure 1 - Polypropylene sling. ctin suture on each side of the aponeurosis make the sling. On other occasions, a similar surgery is also performed using the initial surgery described above. The fascial sling is also placed in the middle urethra equal to that of polypropylene but not in the bladder neck as described in the original technique.

This is a prospective non randomized study, with 959 women suffering from SUI, which took place from 2000 to 2007, in the city of Passo Fundo, Rio Grande do Sul, Brazil. The project was approved by the CEP/UPF/RS Research Committee under Protocol No. 129/2007. All the patients had their previous medical history recorded and a physical examination, a stress test with a full bladder, and an urodynamic study. The slings proposed were: a) an abdominal aponeurotic sling; and b) a polypropylene mesh sling (Marlex $\left.{ }^{\circledR}\right)$. We informed patients as to the advantages and disadvantages between the two types of slings available and the patients were then free to choose which procedure they wished to receive.

The patients were divided into two groups: one in which a segment of aponeurosis of the rectus abdominis muscle (377 women) was used, and the other in which a segment of polypropylene mesh (Marlex $\left.{ }^{\circledR}\right)$ (582 women) to construct the slings. After surgery, and the sample power calculation, 474 patients were selected to participate in the follow-up study, 158 in the aponeurosis group and 316 in the polypropylene group. After the criteria for inclusion or exclusion were established and certain patients had been excluded, the names of the patients were arranged alphabetically and in an ascending order until the calculated sample number was reached. If someone could not participate or could not be located, the next patient on the list was subsequently contacted.

Patients included in this study were between 35 and 70 years old at the time of the surgery, had stress urinary incontinence from intrinsic sphincter insufficiency or urethral hypermobility (pressure point leakage under stress below $60 \mathrm{~cm} \mathrm{H}_{2} \mathrm{O}$ in the first case and 60 to $120 \mathrm{~cm} \mathrm{H}_{2} \mathrm{O}$ in the second, according to McGuire et al. 1993) (11); or mixed urinary incontinence. Women with urogenital dystopia (cystocele larger than grade I, with prolapse of the uterus and/or vaginal vault), and those who had previously undergone surgical procedures for SUI, with failure or recurrence, were excluded. 
The variables measured in the pre-operative medical workup were as follows: age, stated skin color, number of pregnancies/live births, types of births, weight, height, BMI, civil status, level of education, urgency prior to surgery, previous hysterectomy, rectocele, cystocele grade I, Valsalva leak point pressure, urodynamic study with leak point pressure under stress, and a score from 0 to 10 of satisfaction in relation to the bladder symptoms. The remaining variables: post-operative time in years, number of days hospitalized, number of days of vesical catheterization, whether or not there was extrusion/infection of the sling, resolution, frequency of urine leakage in the past 90 days, bladder urgency, score from 0 to 10 of satisfaction in relation to bladder symptoms, were answered in the questionnaire sent to the patients and revised with them during the re-evaluation consultation.

The patients were contacted by telephone about their willingness to participate in the study. The objectives of the study were explained to them, and they were invited to make an appointment for a consultation. The patients who accepted to participate received two questionnaires by mail, which they were requested to complete and sign; the questionnaire about the postoperative variables, and two copies of the free and informed consent form. During the consultations, the patients returned the documents signed, which were read with them, and in cases of questions about the study, the questionnaires were answered together, and they were given a physical examination and a stress test with full bladder. Those patients who were admitted underwent a cystoscopy to rule out erosion of the mesh into the urethral or bladder.

The results were classified according to Blaivas et al. (1991) (12), into three categories: cure - absence of incontinence; improvement - up to one episode of urine leakage in two weeks; and failure - more than one episode of incontinence per week.

As regards the data analyses the statistics program SPSS (v16) was used, initially to perform a descriptive analysis with the frequency distributions, means, and standard deviations. The Chi-square and Fisher's exact tests were used to assess the differences among the variables. The significance level was set at $5 \%$.

\section{RESULTS}

Of the 474 women who underwent surgery for SUI with the sling technique, 158 received a segment of aponeurosis of the rectus abdominis muscle, and in 316 , polypropylene mesh was used to construct the sling. The average age of the aponeurosis group was 55.20 years (range 37 to 69 ), and the polypropylene group had an average age of 55.69 years (range 36 to 69$)(\mathrm{p}=0.495)$. In both groups, the predominant level of education was 4 to 11 years of schooling, the stated color was white, and the civil status was a stable relationship; most women had had two pregnancies and cesarian deliveries. The body measurements in the aponeurosis and polypropylene groups were, respectively: weight: 66.8 and $62.9 \mathrm{~kg}(\mathrm{p}<0.05)$; height: $1.65 \mathrm{~m}$ and $1.64 \mathrm{~m}(\mathrm{p}=0.069)$; and BMI: 24.6 and $23.4(\mathrm{p}<0.05)$. In the urodynamic evaluation, detrusor hyperactivity was observed in 16 women $(10 \%)$ of the aponeurosis group, and 27 (8.5\%) of the polypropylene group (mixed urinary incontinence) $(p=0.692)$; leak point pressure under stress was between 60 and $120 \mathrm{~cm} \mathrm{H}_{2} \mathrm{O}$ in 116 women $(73.5 \%)$ of the aponeurosis group, and $221(70 \%)$ of the polypropylene group (urine loss due to urethral hypermobility) $(\mathrm{p}=0.518)$; leak point pressure under stress below $60 \mathrm{~cm} \mathrm{H}_{2} \mathrm{O}$ in 26 women $(16.5 \%)$ in the aponeurosis group, and 68 $(21.5 \%)$ in the polypropylene group (urine loss from intrinsic sphincter insufficiency) $(p=0.075)$. Not only during the Valsalva leak point pressure test with a full bladder, but also during the urodynamic study, urine leakage was observed in $91.8 \%$ of the aponeurosis group and $92.1 \%$ of the polypropylene group $(\mathrm{p}=$ 0.473 ). In the remaining women, the diagnosis was confirmed by their previous medical history and by the pad test, and they were assigned to the urethral hypermobility group.

Regarding to the clinical aspects, the aponeurosis and polypropylene groups presented as follows, respectively: $52.5 \%$ and $60.4 \%$ reported 3 or more episodes of urine leakage per week ( $\mathrm{p}<0.05) ; 19 \%$ and $20.6 \%$ reported urination urgency $(\mathrm{p}=0.776)$; $14.6 \%$ and $20.3 \%$ had had an hysterectomy ( $\mathrm{p}=$ $0.166) ; 19.6 \%$ and $27.5 \%$ had had a perineoplasty $(\mathrm{p}=0.078) ; 41.8 \%$ and $35.4 \%$ had rectocele $(\mathrm{p}=$ 0.215 ), and $55.7 \%$ and $57.6 \%$ had cystocele G1 (p = $0.768)$; concomitant perineoplasty was carried out in 
Table 1 - Characterization of the women who underwent surgery for urinary incontinence, according to a pre-operative urodynamic study and clinical history.

\begin{tabular}{|c|c|c|c|c|c|}
\hline \multirow{3}{*}{ Variables } & \multicolumn{5}{|c|}{ Group } \\
\hline & \multirow{2}{*}{$\begin{array}{c}\text { Aponeurosis } \\
\text { N }\end{array}$} & \multicolumn{4}{|c|}{ Polypropylene } \\
\hline & & $\%$ & $\mathbf{N}$ & $\%$ & p Value \\
\hline \multicolumn{6}{|l|}{ Urethral hypermobility } \\
\hline PPE: $60-120 \mathrm{~cm} \mathrm{H}_{2} \mathrm{O}$ & 116 & 73.5 & 221 & 70.0 & 0.518 \\
\hline \multicolumn{6}{|l|}{ Intrinsic sphincteric deficiency } \\
\hline PPE: $<60 \mathrm{~cm} \mathrm{H}_{2} \mathrm{O}$ & 26 & 16.5 & 68 & 21.5 & 0.075 \\
\hline Detrusor hyperactivity & 16 & 10 & 27 & 8.5 & 0.692 \\
\hline \multicolumn{6}{|l|}{ Frequency of urine leakage last 90 days pre-op } \\
\hline Up to 1 time per week & - & - & 1 & 0.3 & 0.000 \\
\hline Up to 2 times per week & 32 & 20.2 & 14 & 4.4 & \\
\hline Up to 3 times per week & 83 & 52.5 & 191 & 60.4 & \\
\hline Any movement, sneezing or coughing & 35 & 22.2 & 62 & 19.6 & \\
\hline Even lying down, constant & 8 & 5.1 & 48 & 15.2 & \\
\hline \multicolumn{6}{|l|}{ Urine leakage in pre-op urge stress test } \\
\hline Yes & 157 & 99.4 & 311 & 98.4 & 0.859 \\
\hline No & 1 & 0.6 & 5 & 1.6 & \\
\hline \multicolumn{6}{|l|}{ Pre-operative urgency } \\
\hline Yes & 30 & 19.0 & 65 & 20.6 & 0.776 \\
\hline No & 128 & 81.0 & 251 & 79.4 & \\
\hline \multicolumn{6}{|l|}{ Hysterectomy } \\
\hline Yes & 23 & 14.6 & 64 & 20.3 & 0.166 \\
\hline No & 135 & 85.4 & 252 & 79.7 & \\
\hline \multicolumn{6}{|l|}{ Pre-op perineoplasty } \\
\hline Yes & 31 & 19.6 & 87 & 27.5 & 0.078 \\
\hline No & 127 & 80.4 & 229 & 72.5 & \\
\hline \multicolumn{6}{|l|}{ Pre-op rectocele } \\
\hline Yes & 66 & 41.8 & 112 & 35.4 & 0.215 \\
\hline No & 92 & 58.2 & 204 & 64.0 & \\
\hline
\end{tabular}

$67(42.4 \%)$ and 109 (34.5\%) (p=0.114) (Table-1). The mean number of hospitalization days was 3 and 1.1 days $(\mathrm{p}<0.05)$, and for vesical catheterization was 0.4 and 0.1 days $(\mathrm{p}<0.05)$, for the aponeurosis and polypropylene groups respectively, i.e., was significantly smaller for the polypropylene group. There were no cases of intestinal or vascular perforations or hematomas in either group. There was perforation of bladder with needle in 5 cases in the aponeurosis group, and in 12 cases in the polypropylene group: in all these cases, hematuria was observed in the Foley catheter and urine collector soon after the passage of the needle. This was removed and reinserted closer to the pubis, and the Foley catheter left indwelling for three days, with no consequences in any of the cases $(p=0.72)$. In all the cases of both groups, a transoperative cystoscopy was performed, and no other injury was observed. 
The aponeurosis group had a mean follow-up time of 3.65 years (range 1 to 7 years), and the polypropylene group had a mean follow-up time of 3.56 years (range 1 to 7 years). In the aponeurosis group, 128 cases $(81.0 \%)$ resulted in a cure of SUI, improvement occurred in 23 (14.6\%), and failure in 7 (4.4\%). The polypropylene group showed a cure in 281 cases $(88.9 \%)$, improvement in $23(7.3 \%)$, and failure in 12 $(3.8 \%)$. The rates of cure, improvement, and failure did not differ significantly between the groups $(\mathrm{p}=$ 0.083 ) (Table-2). In the stress test with full bladder (Valsalva), 91\% of the aponeurosis group and 92\% of the polypropylene group showed no urine leakage $(p=0.859)$. The patients who presented a single improvement in both groups were referred for pelvic physiotherapy with poor adhesion. Urinary urgency was observed in $19(12 \%)$ of the aponeurosis group and $28(8.9 \%)$ of the polypropylene group $(\mathrm{p}=0.320)$ and were treated with anticholinergic therapy.

We classified extrusion and/or infection of the sling together, because there was vaginal secretion in both cases. In the aponeurosis group, 7 (4.4\%) had a vaginal extrusion/infection, and of the polypropylene group, $15(4.7 \%)$ had this condition $(\mathrm{p}=0.877)$ (Table-2). In the cases of vaginal extrusion/infection in the aponeurosis group, $2(28.6 \%)$ resolved spontaneously and $5(71.4 \%)$ required surgical removal. As regards the cases of vaginal extrusion/infection in the polypropylene group, $5(31.2 \%)$ resolved spontaneously and $11(68.8 \%)$ required surgical removal $(\mathrm{p}=$ 0.899) (Table-2). The patients with extrusion / sling infection received fibrinolysin 3 times a day for two weeks. Those who did not improve underwent surgery with removal of infected or exposed sling but later started to have leaking urine. After 6 months, some patients underwent surgery again with the polypropylene sling. After the second surgery, the majority of them had some degree of temporary urgency.

Six women $(3.8 \%)$ in the aponeurosis group and $7(2.2 \%)$ in the polypropylene group $(p=0.374)$ underwent urethrolysis within 60 days, due to urine retention (Table-2). All patients had improvement in urinary flow and bladder emptying, but also showed some degree of urgency. In our experience, the patients who required surgery again complained of some urinary urgency, had a low adherence to anticholinergic medication but improved after 90 to 180 days with pelvic floor exercises or because of the body adjustment over time.

A cystoscopy was performed after more than one year after the surgery, in $66(41 \%)$ patients in the

Table 2 - Number and frequency of urine leakage, vaginal extrusion/infection with resolution and retention/urethrolysis in women who underwent the surgical sling technique for SUI with aponeurosis or polypropylene.

\begin{tabular}{|c|c|c|c|c|c|}
\hline \multirow{3}{*}{ Variables } & \multicolumn{5}{|c|}{ Group } \\
\hline & \multicolumn{2}{|c|}{ Aponeurosis } & \multicolumn{3}{|c|}{ Polypropylene } \\
\hline & $\mathbf{N}(158)$ & $\%$ & $\mathbf{N}(316)$ & $\%$ & p Value \\
\hline \multicolumn{6}{|l|}{ Urine leakage last 90 days (post op) } \\
\hline Never & 128 & 81.0 & 281 & 88.9 & 0.083 \\
\hline Up to once in two weeks & 23 & 14.6 & 23 & 7.3 & \\
\hline More than once a week & 7 & 4.4 & 12 & 3.8 & \\
\hline \multicolumn{6}{|l|}{ Vaginal extrusion/infection } \\
\hline Yes & 7 & 4.4 & 15 & 4.7 & 0.877 \\
\hline No & 151 & 95.6 & 301 & 95.3 & \\
\hline \multicolumn{6}{|l|}{ Resolution extrusion/infection } \\
\hline Spontaneous & 2 & 28.6 & 5 & 31.2 & 0.899 \\
\hline Surgical removal of the sling & 5 & 71.4 & 10 & 68.8 & \\
\hline \multicolumn{6}{|l|}{ Retention urethrolysis after 60 days } \\
\hline Yes & 6 & 3.8 & 7 & 2.2 & 0.374 \\
\hline No & 152 & 96.2 & 309 & 97.8 & \\
\hline
\end{tabular}


Polypropylene and Aponeurotic Slings

Table 3 - The mean of the scores from 0 to 10, given by the patients prior and after the procedure with aponeurosis or polypropylene sling.

\begin{tabular}{lccccc}
\hline Variable & Group & N & Mean & SD & p Value \\
\hline Score 0-10 & Aponeurosis & 158 & 2.2 & 1.4 & 0.000 \\
(satisfaction prior procedure) & Polypropylene & 316 & 2.1 & 1.3 & \\
Score 0-10 & Aponeurosis & 158 & 9.4 & 1.2 & 0.000 \\
(satisfaction after procedure) & Polypropylene & 316 & 9.6 & 1.0 & \\
& & & & \\
\hline
\end{tabular}

aponeurosis group and $146(46.2 \%)$ in the polypropylene group. There were no cases of sling erosion to the bladder or urethra in both groups $(\mathrm{p}=0.414)$.

The average scores from 0 to 10 given by the patients after the surgery (9.4) and (9.6), respectively to aponeurosis and polypropylene, showed a great improvement in both groups over the mean scores (2.2) and (2.1) that they gave prior to surgery. Student's-ttest for paired samples indicated a significant difference between the mean pre- and post-operative scores in the aponeurosis group $(\mathrm{p}=0.000)$, and also in the polypropylene group $(\mathrm{p}=0.000)($ Table-3) .

\section{COMMENTS}

The objective of surgical treatment for SUI in women is to re-establish urethral resistance, in order to prevent urine leakage during an increase in abdominal pressure, preserving adequate bladder filling for voluntary and spontaneous urination.

Studies comparing commercially available synthetic slings with the pubovaginal fascial sling or Burch's colposuspension (13-17) have shown that these slings are promising, but there is still the question of cost, which is prohibitive in our situation. The option of an aponeurotic sling either from the rectus abdominis or a polypropylene mesh for the surgeon to use to construct the sling appears to be an accessible procedure, and the cost is compatible with the conditions in our clinical working environment.

After several years using both the aponeurosis made from the rectus abdominis and the polypropylene sling, we have established two cohorts of patients whom are currently being monitored. Upon comparing both products and data reported in the literature, it appears that the polypropylene sling is a viable procedure and that it can be used with results and rates of complications comparable to the aponeurosis, if the procedure is carried out with technical rigor, rapid surgery, minimal exposure of the surgical field, a small incision, good tissue padding, etc.

In our study, we observed extrusion or infection of the sling in $4.7 \%$ of the polypropylene group and $4.4 \%$ of the aponeurosis group. In a doctoral thesis, de Almeida et al. (18) described an experiment in rats using slings composed of autologous fascia, pig intestine submucosa, tension-free vaginal tape (TVT) and Marlex ${ }^{\circledR}$. These authors concluded that the material that caused the least inflammatory reaction and produced the least collagen was the autologous fascia. The TVT and the Marlex ${ }^{\circledR}$ produced similar reactions.

Furthermore, in our study, with an average follow-up time of 3.56 and 3.65 years for the polypropylene and aponeurosis groups, the mean of the scores from 0 to 10 given by the patients after the procedure indicated high satisfaction in relation to the mean score that they assigned prior to the procedure, with both techniques $(p=0.000)$. Haab et al. (19), with 4 years of follow-up of a pubovaginal sling for the treatment of SUI for intrinsic sphincter insufficiency and using an self-assessed questionnaire, confirmed the high satisfaction rate of the patients, in spite of their symptoms of urinary urgency. Rodrigues et al. (20), using polypropylene mesh for the construction of sling for SUI, concluded that the complications and cure rates can be compared with TVT, and should be 
considered an alternative for patients with SUI. Amaro et al. (21), with a prospective randomized study of quality of life after autologous fascial sling and TVT for SUI, had similar results between the AFS and TVT, except that the operative time was shorter in the TVT.

In our 16 cases of vaginal extrusion/infection in the polypropylene group, 5 (31.2\%) spontaneously resolved, and $11(68.8 \%)$ required surgical removal of the sling. In the 7 cases of vaginal extrusion / infection of the aponeurosis group, 2 (28.6\%) spontaneously resolved and $5(71.4 \%)$ required surgical removal. Woodruff et al. (22) carried out a comparative histological study of sling materials in women who underwent the repair, in which a portion of the sling was removed in order to analyze the inflammatory response, encapsulation, neovascularization, and fibroblastic infiltration. The tissues analyzed were polypropylene, aponeurosis (autologous fascia), pig fascia, and fascia from cadavers. There was no degradation of the polypropylene insert, and the degree of fibroblastic infiltration was better. Also greater neovascularization was found in the polypropylene and aponeurotic slings. There was no encapsulation of the polypropylene or the aponeurosis. Giant cells were found in the pig fascia, and these were encapsulated to the highest degree. There was greater degradation of the cadaver fascia. Almeida et al. (23) describe a modification of the cadaveric prolapse repair and sling using cadaveric fascia lata fixed over rectus abdominis muscle. After an average of 6 months they observed $65 \%$ cure rate of incontinence and $12 \%$ improvement of incontinence but did not report any degradation of the fascia.

Cystoscopy was performed during surgery in all patients and bladder perforation was observed in $0.36 \%$. Although hematuria was present in the Foley catheter, suggesting drilling, we concluded that cystoscopy is necessary when a retropubic sling is used, unlike Fischer et al. (24), who concluded that a transobturator sling is as effective as the retropubic sling, and does not require cystoscopy.

In our study, patients resulted in failure, 7 aponeurotic group, and 12 in the polypropylene group needed surgery again. We repeated the procedure with a polypropylene sling (Marlex ${ }^{\circledR}$ ), avoiding any local manipulation and found a satisfactory improve- ment. We avoided dissecting the tape adhered to the periurethral tissues, as proposed by Eandi et al. (25), who used TVT for the correction of SUI in women who had undergone a synthetic sling, with failure of the procedure.

\section{CONCLUSIONS}

The use of a segment of polypropylene mesh (Marlex ${ }^{\circledR}$ ) for the construction of a sling for urinary incontinence in women is safe and effective in improving and cure of patients. It is easy to perform, inexpensive, showed low failure rates and low rates of extrusion / infection in this study, however, further studies with other materials will be required to select the ideal sling.

\section{CONFLICT OF INTEREST}

None declared.

\section{REFERENCES}

1. Blaivas JG, Olsson CA: Stress incontinence: classification and surgical approach. J Urol. 1988; 139: 727-31.

2. Abrams P, Cardozo L, Fall M, Griffiths D, Rosier P, Ulmsten U, et al.: The standardisation of terminology of lower urinary tract function: report from the Standardisation Sub-committee of the International Continence Society. Neurourol Urodyn. 2002; 21:1 67-78.

3. Hannestad YS, Rortveit G, Sandvik H, Hunskaar S; Norwegian EPINCONT study. Epidemiology of Incontinence in the County of Nord-Trøndelag. A community-based epidemiological survey of female urinary incontinence: the Norwegian EPINCONT study. Epidemiology of Incontinence in the County of Nord-Trondelag. J Clin Epidemiol. 2000; 53: 1150-7.

4. Leach GE, Dmochowski RR, Appell RA, Blaivas JG, Hadley HR, Luber KM, et al.: Female Stress Urinary Incontinence Clinical Guidelines Panel summary report on surgical management of female stress urinary incontinence. The American Urological Association. J Urol. 1997; 158: 875-80. 
5. Albo ME, Richter HE, Brubaker L, Norton P, Kraus SR, Zimmern PE, et al.: Burch colposuspension versus fascial sling to reduce urinary stress incontinence. $\mathrm{N}$ Engl J Med. 2007; 356: 2143-55.

6. Rofeim O, Yohannes P, Badlani GH: Minimally invasive procedures for urethral incontinence: is there a role for laparoscopy? Int Braz J Urol. 2002; 28: 403-12.

7. Appell RA: Techniques and results in the implantation of the artificial urinary sphincter in women with type 3 stress urinary incontinence by vaginal approach. Neurourol Urodyn. 1988; 7: 613-9.

8. Cross CA, Cespedes RD, McGuire EJ: Our experience with pubovaginal slings in patients with stress urinary incontinence. J Urol. 1998; 159: 1195-8.

9. Chaikin DC, Rosenthal J, Blaivas JG: Pubovaginal fascial sling for all types of stress urinary incontinence: long-term analysis. J Urol. 1998; 160: 1312-6.

10. Almeida SH, Gregòrio E, El Sayed S, Fraga FC, Moreira HA, Rodrigues MA: Variables predictive of voiding disfunction following aponeurotic sling surgery: multivariate analysis. Int Braz J Urol. 2004; 30: 302-6.

11. McGuire EJ, Fitzpatrick CC, Wan J, Bloom D, Sanvordenker J, Ritchey M, et al.: Clinical assessment of urethral sphincter function. J Urol. 1993; 150: 14524.

12. Blaivas JG, Jacobs BZ: Pubovaginal fascial sling for the treatment of complicated stress urinary incontinence. J Urol. 1991; 145: 1214-8.

13. Norris JP, Breslin DS, Staskin DR: Use of synthetic material in sling surgery: a minimally invasive approach. J Endourol. 1996; 10: 227-30.

14. Corujo M, Badhani G: The use of synthetic material in the treatment of women with SUI lends strength and disability. Contemp Urol. 1999; 11: 76-80.

15. Palma PC, Riccetto CL, Dambros M, Herrmann V, Thiel M, Netto NR Jr: Tension-free vaginal tape (TVT): minimally invasive technique for stress urinary incontinence (SUI). Int Braz J Urol. 2002; 28: 45863.

16. Silva-Filho AL, Triginrlli SA, Noviello MB, SantosFilho AS, Pires CR, Cunha-Mello: Sling pubovaginal for treatment of stress urinary incontinence by urethral hypermobility and sphincter insufficiency. Int Braz J Urol. 2003; 29: 540-4.

17. Rutman M, Itano N, Deng D, Raz S, Rodríguez LV: Long-term durability of the distal urethral polypropylene sling procedure for stress urinary incontinence: minimum 5-year followup of surgical outcome and satisfaction determined by patient reported questionnaires. J Urol. 2006; 175: 610-3.
18. de Almeida SH, Rodrigues MA, Gregório E, Crespígio $\mathrm{J}$, Moreira HA: Influence of sling material on inflammation and collagen deposit in an animal model. Int $\mathrm{J}$ Urol. 2007; 14: 1040-3.

19. Haab F, Trockman BA, Zimmern PE, Leach GE: Results of pubovaginal sling for the treatment of intrinsic sphincteric deficiency determined by questionnaire analysis. J Urol. 1997; 158: 1738-41.

20. Rodrigues FR, Maroccolo Filho R, Maroccolo RR, Paiva LC, Diaz FA, Ribeiro EC: Pubovaginal sling with a low-cost polypropylene mesh. Int Braz J Urol. 2007; 33: 690-4.

21. Woodruff AJ, Cole EE, Dmochowski RR, Scarpero HM, Beckman EN, Winters JC: Histologic comparison of pubovaginal sling graft materials: a comparative study. Urology. 2008; 72: 85-9.

22. Amaro JL, Yamamoto H, Kawano PR, Barros G, Gameiro MO, Agostinho AD: Clinical and quality-of-life outcomes after autologous fascial sling and tensionfree vaginal tape: a prospective randomized trial. Int Braz J Urol. 2009; 35: 60-6; discussion 66-7.

23. Almeida SH, Gregório EP, Saquetti EE, Moreira HA, Fraga F, Rodrigues MA: Use of cadaveric fascia lata to correct grade IV cystocele. Int Braz J Urol. 2003; 29: 48-51; discussion 51-2.

24. Fischer A, Fink T, Zachmann S, Eickenbusch U: Comparison of retropubic and outside-in transoburator sling systems for the cure of female genuine stress urinary incontinence. Eur Urol. 2005; 48: 799-804.

25. Eandi JA, Tanaka ST, Hellenthal NJ, O’Connor RC, Stone AR: Self-reported urinary continence outcomes for repeat midurethral synthetic sling placement. Int Braz J Urol. 2008; 34: 336-42; discussion 343-4.

Accepted after revision: November 03, 2009

\section{Correspondence adrress:}

Dr. Jorge Antonio Winckler

Rua Uruguai 1992/202

Passo Fundo, RS, 99010-112, Brazil

E-mail: jorgewinckler@uol.com.br 


\section{EDITORIAL COMMENT}

The authors review a large number of female patients who were treated for stress urinary incontinence with either a pubovaginal sling using autologous fascia or one made of polypropylene mesh. The authors fashioned their own sling and did not use an industry manufactured kit. Their follow-up was over 3 years and the patient population included no truly elderly patients, with the oldest patient being 70 years of age. The patients were randomized by personal choice after a review of options available. Findings included that the days of hospitalization were markedly less (3 vs. 1.1) for the mesh sling versus the autologous fascial sling and that the rates of vaginal extrusion and infection were similar to both populations. In addition, the number of patients who required urethrolysis secondary to obstructive voiding dysfunction was markedly similar.

The authors should be commended on publishing the results on a large population of patients and the results of their experience. That these surgeons were able to reach a level of success that compared to the gold standard pubovaginal sling with autologous fascia using a self-made mesh sling makes a strong statement regarding the need for industrial supplied kits. This finding has been noted by other thought leaders and warrants contemplation by the reader (1).

\section{REFERENCE}

1. Rutman M, Itano N, Deng D, Raz S, Rodríguez LV: Long-term durability of the distal urethral polypropylene sling procedure for stress urinary incontinence: minimum 5-year followup of surgical outcome and satisfaction determined by patient reported questionnaires. J Urol. 2006; 175: 610-3.

Dr. Steven P. Petrou Professor of Urology, Associate Dean Mayo School of Graduate Medical Education Jacksonville, Florida, USA E-mail:petrou.steven@mayo.edu 